\title{
대학생이 지각한 교수의 지지, 학습동기 및 학업적응의 관계모형 검증
}

\section{논문 요약}

본 연구는 대학생이 지각한 교수의 지지, 학습동기 및 학업적응 간 관계모형을 설정하고, 교수의 지지와 학업 적응의 관계에서 학습동기의 매개효과를 검증하고자 하였다. 선행변인으로서 교수의 지지, 매개변인으로서 학습 동기가 대학생의 학업적응에 영향을 미친다고 가정하였다. 이를 위해 대학생 240 명을 대상으로 자기보고식 설 문지를 통하여 자료를 수집하였다. 본 연구문제를 검증하고자 상관분석과 구조방정식모형 검증을 실시하였다. 본 연구를 통하여 얻어진 결과를 요약하면 다음과 같다. 첫째, 교수의 지지는 대학생의 학습동기와 학업적응에 긍정적인 영향을 미쳤고, 특히 교수의 정서적 지지가 가장 설명력이 높았다. 둘째, 교수의 지지를 예언변인으로, 학습동기를 매개변인으로, 학업적응을 결과변인으로 설정한 본 연구의 부분매개모형이 완전매개모형보다 더 적 합한 것으로 나타났다. 셋째, 부분매개모형에 제시된 3개의 경로 [(교수의 지지 $\rightarrow$ 학업적응), (교수의 지지 $\rightarrow$ 학습 동기), (학습동기 $\rightarrow$ 학업적응)] 모두 유의미한 것으로 나타났다. 넷째, 교수의 지지와 학업적응 간 관계에서 학습 동기가 매개변수로 작용하는 것으로 나타났다. 본 연구의 결과를 토대로 대학생의 학습동기와 학업적응을 높이 기 위한 방안을 논의하였다.

주요어 : 교수의 지지, 학습동기, 학업적응, 대학생

* 제 1 저자, 동신대학교 원격평생교육원 연구원

** 동신대학교 대학원 교육학과 박사과정 수료

*** 교신저자, 동신대학교 교육대학원 교수 


\section{I. 서론}

\section{1. 연구의 필요성 및 목적}

대학생 시기의 원만한 학업적응은 학교생활의 전반적 적응을 예측할 수 있는 중요한 단서가 된다. 그리고 학교생활의 적응 여부는 전반적인 심리·사회적 적응과 관련되기 때문에(우성희, 2011), 한 개인에게 대학생 시기는 사회 구성원으로서 살아가는데 필요한 인간관계기술을 습득 하고 전공분야에 대한 전문지식과 기술을 익혀 사회로 진출하기 위한 준비과정이라 할 수 있다. 이 과정에서 학문을 접하고 사회변화의 흐름을 감지하며, 직업인으로서 갖추어야 할 전문지식과 행동요령을 습득하여야 한다(노충래, 2002). 학교생활에서의 성공적인 적응은 여러 영역들에 잘 적응하는 것도 중요하지만 학업적응 영역에서의 만족할만한 성취가 전반적인 학교생활적응을 성공적으로 이끌어 낼 수 있으므로(장경문, 2005), 학교생활적응에서 가장 우선적인 것은 학업적 적응이다(성선진, 2010).

학업관련 적응의 어려움을 극복하는 데에는 학습자의 노력도 중요하지만 인적 환경에서의 사 회적 지지와 같은 지원이 중요한 요인으로 작용한다(Ghaith, 2002; Legault, Green-Demer, \& Pelletier, 2006). 사회적 지지는 학습자의 성취동기나 자기효능감과 관계가 있고 이는 학습자의 학업성취와도 직접적인 관계가 있으며(Legault, Green-Demers \& Pelletier, 2006), 개인의 적응과 발달(Ghaith, 2002)에도 영향을 미친다. 사회적 지지를 받지 못한다고 지각한 사람들은 적응에 어려움을 겪고, 생활 만족도가 떨어지지만(김연수, 1995), 사회적 지지를 많이 받으면 자신이 더 유능하고 성공적이며 적응을 더 잘 할 수 있다고 평가하게 만든다(옥경희, 2001). 이와 같이 사회 적 지지는 심리적 안녕감을 증진시키고 지지를 통한 만족감은 심리적 건강에 영향을 미친다 (Chien-Huey Chang, \& Schaller, 2000; Kef, S., 1997, 2002).

학습장면에서 성공적인 학업적응을 위하여 간과할 수 없는 것은 학습자는 학습과정에서 환경 과 끊임없이 상호작용을 한다는 것이다(김현진, 정재학, 2011). 특히 학습과정은 자기조절, 학업 수행의 평가와 결과로 이루어지며(Efklides, 2001) 인간과 과제 특성, 학습과정의 계속되는 평가 와 결과에 영향을 받는 과정에서 정서가 유발된다(Efklides \& Volet, 2005). 그 중 교수자의 지지 나 태도 등은 학습자의 인지와 정서에 영향을 미치는 중요 요소로 지적되고 있어서(Kunter et al., 2008; Metcalfe \& Game, 2006) 교수자 변인은 대학생활적응의 보호요인으로 작용한다(김성 경, 2003).

우리나라 대학생들은 초·중등학교 시기와 상당히 다른 수업방식과 상호작용 방식으로 인해 학업 포기나 소극적인 자세를 보이기도 한다(정은이, 박용한, 2008). 그러므로 이들의 성장과 발 달을 돕는 교수의 체계적인 역할이 필요하다. 대학에서 교수의 역할은 대학생들에게 대학생활과 
교육, 장래 진로까지 직접적인 위치에서 영향을 미치는 대학교육의 주체이다(김선연, 김효진, 2012). 그러나 대학생의 사회적 지지원 들 중 의미 있는 타인인 교수와의 관계를 살핀 연구는 매우 드물다. 이는 대학에서 교수와 학생간의 상호작용은 주로 수업시간을 통해서 이루어지고, 학년마다 지도교수가 정해져 있으나 초·중등학교에서의 교사-학생의 관계처럼 정기적이고 빈번 하게 유지되지 않는 경향(정은이, 박용한, 2008) 때문으로 보인다. 초·중등학생을 대상으로 학업 적응을 다룬 연구들도 교사의 지지를 사회적 지지의 하위요인의 하나로 다룬 연구들(소연희, 2008; 윤소영, 주자영, 이은영, 2013; 정규석, 2004; 최지은, 신용주, 2003)이 대부분으로, 학교현장 에서 교수자의 지지와 학습자의 학업적응의 관계성에 초점을 맞추지 못하고 있다.

또한 교수자의 지지와 학습자의 학업적응의 관계에서 고려해야 할 사항은 교수자의 지지가 학습동기와 연결될 것인가의 문제이다. 먼저, 학습동기는 학습이 일어나게 하는 원동력으로서 학습자로 하여금 과제를 선택하게 하고 과제의 해결을 위해 노력하게 하며 학습상의 난관에 부 딪힐 때도 인내심을 갖고 학습을 지속하게 하는 것으로 교수-학습 상황에서 매우 중요하게 고려 해야 할 변인으로 인식되고 있다(한순미, 2004). 학습동기는 일반적으로 학습목표의 성취를 위하 여 학습행동을 유발하고 유지시키며 조절시키는 과정을 포괄하는 심리적 구인이다(정은이, 박용 한, 2008). 의미 있는 타인과의 관계는 학습동기를 증진시키는 요인인데(Furrer \& Skinner, 2003), 교수자의 지지는 학습자의 학습동기에 긍정적인 영향을 미치며(김종렬, 2012; 김현진, 정재학, 2011; 이숙정, 2006; 이윤정, 2004; Kunter et al., 2008; Lau \& Mie, 2008), 성공적인 학업수행을 위해서는 학습자가 학습상황에서 자신의 효능에 대한 인식 수준이 높아야 하기 때문에 (Bandura,1977; Schunk, 1989). 학습동기는 학업에 영향을 미치는 요인이며(김명희, 하정희, 2008; 류관열, 엄우용, 최성열, 2008; 한순미, 2004), 결과적으로 학교적응에도 긍정적으로 작용한 다(김일태, 허남진, 2004; 정은이, 박용한, 2008; 추미애, 박아청, 2006; Eisenberg, Spinard \& Morris, 2000).

또 하나 고려할 사항은 교수자의 지지와 학업적응의 관계에서 학습동기가 매개자 역할을 할 것인가 하는 문제이다. 이와 관련하여 초중등학생들을 대상으로 사회적 지지, 학업적 자기효능 감 및 성취동기와 학업성취와의 관계를 살펴본 연구들(문승태, 김민배, 2005; 소연희, 2008; Legault, Green-Demer, \& Pelletier, 2006)과 사회적 지지, 자기효능감, 학교생활적응의 관계를 살펴본 연구(성선진, 2010)에 의하면 사회적 지지의 하위요인인 교사의 지지와 적응의 관계를 다루면서 학업적 자기효능감이나 성취동기와 같은 동기적 요인이 이 두 요인의 관계를 매개한 다는 것을 밝히고 있다. 이러한 점을 고려해볼 때 대학생 집단에서도 교수의 지지가 학습에 대한 동기적 요인이나 학업적응과 관계가 있을 것으로 가정해볼 수 있다.

그러나 교수의 지지와 학습동기, 그리고 학업적응에 이르는 경로를 살펴본 연구는 미비하다. 본 연구를 통해 각 요인들 간의 구조관계를 통합적으로 이해한다면 대학생의 학업부적응을 예 
방하고, 학습지도를 위한 기초자료 및 학습동기의 향상을 위한 교수자의 역할에 대한 시사점, 학업적응을 위한 상담 및 교육 프로그램 개발과 개입전략에 필요한 이론적인 자료를 얻을 수 있을 것으로 본다.

\section{2. 연구문제}

본 연구에서는 교수의 지지와 학습동기, 그리고 학업적응의 관련성을 알아보고, 교수의 지지 가 대학생의 학습동기와 학업적응에 어떻게 작용하는지 알아보고자 한다. 그리고 교수의 지지와 학업적응의 관계에서 학습동기가 매개자 역할을 하는지 알아봄으로써 대학의 교수-학습활동 및 학습지도에 필요한 시사점을 얻고자 한다.

본 연구에서 살펴보고자 하는 연구문제는 다음과 같다.

연구문제 1. 교수의 지지와 대학생의 학습동기 및 학업적응은 어떠한 관계가 있는가?

연구문제 2. 교수의 지지는 학습동기를 매개로 하여 대학생의 학업적응에 영향을 미치는가?

연구문제 3. 교수의 지지와 학습동기의 학업적응에 대한 직간접적인 영향력은 어떠한가?

\section{П. 이론적 배경}

\section{1. 대학생의 학업적응과 교수의 지지}

대학생 시기는 청소년기를 벗어나 성인기로 향하는 출발점에서 심리적·정서적으로 매우 불안 정한 시기로(정여주, 홍성례, 2012) 대학 입학과 함께 고등학교 시절까지의 수동적이고 타율적인 행동규범과는 다른 자율적 사고와 책임 있는 행동을 요구받게 되어 혼란과 불안을 경험하게 된 다(권재환, 이성주, 2013). 우리나라 대학생들은 많은 시간을 학교에서 보내고 있고, 발달단계상 후기 청소년기 또는 성인초기에 해당되는 시기이며(하정희, 정은선, 송수민, 2011), 청소년이 성 인기로 진입하는 시기가 점점 늦춰지고 있는 점(Furstenberg, Rumbaut, \& Settersten, 2005; Shanahan, 2000)들을 감안하면 대학생에게 있어서 교수는 부모 다음으로 밀접하게 상호작용하 는 성인이라고 볼 수 있다. 그러나 대학에서 교수-학생의 상호작용은 피상적인 관계가 되기 쉽고 이러한 교수-학생의 관계로 인하여 학생들은 강의나 학과활동에 소극적인 참여를 하는 경향이 있으며 그 결과 학교몰입에 어려움을 갖게 되므로 적응의 문제는 대학에서도 반드시 논의되어 야 한다(정은이, 박용한, 2008). 특히, 대학에서 교수의 역할이 점점 중요해지고 있는(김선연, 김 효진, 2012) 상황에서 대학생의 적응에 교수의 지지가 어떤 역할을 하는지 밝히는 일은 중요한 
의미를 지닌다.

그동안 학업적응을 다룬 연구들은 학교생활적응에서 학업적응이 무엇보다도 중요하다는 점을 인식하면서도 이를 학교생활적응의 하위요인으로 다루고 있어서 학업적 어려움을 극복할 수 있 고 또 학업성취도를 향상시킬 수 있는 구체적 방안에 대한 근거를 도출하는데 부족한 점이 있었 다. 학교생활적응의 관련요인을 광범위하게 탐색한 성선진(2010)은 학교생활과 관련하여 적응을 다룬 연구들은 학교활동의 매우 다양한 내용들을 포함시키고 있지만 가장 우선적인 것은 학업적 응이라고 하면서 학업적응의 구성요소를 수업참여, 학습노력, 학습지속성, 학습행동통제로 구분 하였다. 이에 본 연구에서는 학업적응의 개념을 학습자의 학업적 욕구와 성취를 충족하기 위하여 학습자 자신을 지속적으로 변화시키는 적극적이고 창조적인 과정으로 정의하고자 한다.

한편 적응과 관련하여 교수자의 지지를 다룬 연구들은 주로 초·중등학교급의 청소년들을 대 상으로 한 연구들이 주류를 이루는데, 대부분 사회적 지지의 하위요인으로 다루고 있다(문은식, 김충희, 2002; 정규석, 2004; 최지은, 신용주, 2003; Rosenfeld, Richman, \& Bowen, 2000).

이들 연구들을 살펴보면 사회적 지지원을 부모나 가족, 교사, 또래나 친구 등으로 구분하고 있어서 주로 개인의 사회적 관계망에서의 중요한 타인을 하위요소로 구분하고 있다. 또한 사회 적 지지의 구성요소에 대해서는 매우 다양한 주장들이 있어왔다. 예컨대, Lowcntthal(1999)는 사 회적 지지의 구성요소를 지지원들에 의해 제공되는 정서적, 정보적, 도구적, 물질적 도움으로 구 분하였고, Turner-Cobb(2002)는 정서적 지지, 존중의 지지, 관계망 지지로 구분하여 설명하고 있 다. 지지원을 부모, 교사, 친구로 구분하여 사회적 지지 척도를 개발한 Nolten(1994)은 정서적, 정보적, 물질적, 평가적 지지로 구분하였다. 이에 본 연구에서는 선행연구들과 Nolten(1994)의 구분을 토대로 하여 교수의 지지를 대학생의 교수와의 상호작용을 통하여 제공되거나 제공받고 있다고 지각하는 정서적, 정보적, 도구적, 평가적 지지하고 정의하고자 한다.

학교현장에서 교수자 변인과 관련된 선행연구들은 학습자가 지각한 교수자의 지지, 태도, 행 동이 학업에 미치는 영향에 대하여 연구되어왔다. 선행연구들은 교수자의 지지와 학업적응간의 긍정적 관계가 있음을 밝히고 있다(Dubow \& Tisak, 1989; Dubow, Tisak, Causey, \& Hryshko, 1991; Ford \& Sutphen, 1996). 학교현장에서 교수자의 지지는 학업성취와 학업능력을 높이고 시 험수행능력, 등급을 향상시키며(Alva, 1991; Goldsmith \& Albrecht, 1993; Cutrona, Cole, Colangelo, Assouline, \& Russell, 1994) 학생들의 학업적응과 전반적인 발달(Clark, 1991)에 기여 한다. 최근의 국내 연구들도 사회적 관계요인들 중 교수자와의 관계가 학습자의 적응에 영향을 미치는 변인임을 밝히고 있다(윤소영, 주자영, 이은영, 2013; 정규석, 2004; 최지은, 신용주, 2003).

먼저 교수자의 지지와 학습자의 적응문제를 다룬 초·중등학교급의 청소년들을 대상으로 한 연구들을 살펴보면, 교사의 지지는 사회적 기술의 향상이나 학교부적응 감소와 관련이 있고(문 은식, 김충희, 2002), 교사가 지지적 일수록 학교생활의 흥미와 학업성취도가 높은 것으로 나타 
났다(정규석, 2004; 최지은, 신용주, 2003; Rosenfeld, Richman, \& Bowen, 2000). 교사의 지지와 유사한 변인에 대한 연구도 있는데, 교사와의 친밀감이 학생의 학교생활적응과 높은 상관이 있 음을 밝힌 연구(이윤정, 2004), 학생이 교사의 태도를 긍정적으로 지각할수록 학교생활적응을 잘 한다는 연구(박희자, 2003), 교사와의 관계를 부정적으로 지각하는 학생일수록 학업성취도가 낮 을 뿐 아니라 비행 및 또래관계에 문제를 나타낼 가능성이 많다는 연구(이경아, 정현희, 1999), 그리고 교사에 대한 신뢰가 학교생활적응에 긍정적인 영향을 미친다는 연구(김정화, 김언주, 2006) 등이 있다. 윤주(2001)는 교사가 학생에 대한 피드백을 꾸준히 해 줄 것을 강조하고 학생이 교사에 대한 친밀감이나 신뢰감을 느끼지 않는다면 학교현장에 적응하기 힘들다고 하였다. 봉미 미, 황아름과 송주연(2010)은 교사의 말과 행동이 학습자의 학업성취에 영향을 미친다고 보고하 였다. 이 연구들을 통하여 교사의 지지를 비롯한 교사와의 긍정적인 관계가 학생의 학교생활 전 반 및 학업적응에 영향을 미친다는 것이 밝혀졌다.

대학생을 대상으로 학업적응과 관련하여 교수-학생 간 관계를 주제로 한 연구들을 살펴보면, 이경림과 박재국(2007)은 장애대학생의 대학생활적응과 사회적 지지에 관한 연구를 통해 사회 적 지지가 대학생활적응의 하위 영역인 사회적 적응과 학업적 적응에 영향을 미친다고 보고하 였다. 또한 정은이와 박용한(2008)은 대학생활적응과 관련하여 교수와의 친밀감, 개방성이 대학 생들의 학업적응을 예측하는데 영향력이 있다고 보고하였다. 즉, 대학생을 대상으로 한 연구들 에서도 교수와의 관계가 친밀하고 개방적일수록 학업적응을 더 잘할 수 있다는 것이다. 따라서 본 연구에서는 교수의 지지가 대학생의 학업적응에 영향을 줄 것이라고 가정하였다.

\section{2. 학업적응에 대한 교수의 지지와 학습동기의 영향}

앞에서 살펴본 바와 같이 교수의 지지는 학업적응에 영향력이 있는 요인이다. 대학생의 학업 적응력을 높이기 위해서는 교수와 학생간의 신뢰적 관계와 지지적 행동을 통해 학습동기를 높 이는 것이 필요하다. 학습동기 척도를 한국의 실정에 맞게 표준화하여 개발한 김아영(2002)은 학습동기를 두 개의 하위요인으로 구분하고, 학습자가 자신의 수행능력에 대해 보이는 기대나 신념인 학업적 자기효능감 요인과 함께 자신의 실패경험에 대하여 건설적으로 반응하느냐 비건 설적으로 반응하느냐를 측정하는 실패내성 요인을 포함시켰다. 실패내성이란 실패 결과에 대하 여 비교적 건설적인 태도로 반응하는 경향성으로서, 한국 학생들은 끊임없는 도전과 평가, 경쟁 속에서 실패를 경험하면서 생활하기 때문에 실패내성은 한국의 교육현장에서와 같이 고도의 입 시 경쟁 속에서 살아가야 하는 학생들에게 필요한 속성이라고 하였다.

또한 자기결정성이론(self-determination theory)에 의하면 인간은 자율성, 유능성, 관계성이라 는 세 가지 심리적 욕구를 가지고 있는데, 이 욕구들이 충족될수록 더 행복하고 더 높은 수준의 
내재적 동기를 갖게 되며, 더 많은 성과를 낼 수 있다(Deci \& Ryan, 1985; Ryan \& Deci, 2000). 즉, 학습에 대한 선택권이 개인에게 부여되는 자율성의 증진과 학습에 대한 자신감인 유능성 뿐 만 아니라 주변의 사람들과 좋은 관계를 맺고 싶은 관계유지욕구인 관계성이 증진되면 학습동 기가 향상된다. 특히 대학생 시기는 개인의 독립적이고 능동적인 생활방식으로 전환이 요구되 고, 가족이나 또래 중심의 제한된 관계에서 벗어나 확장된 대인관계를 경험하게 되면서 다른 어 느 시기보다 건강한 대인관계를 형성하는 것이 중요한 발달과제로 대두되기 때문에(이수진, 2009), 관계성의 욕구는 인간의 개인 내적인 동기로 작용할 뿐만 아니라 개인의 적응과도 밀접한 관련성이 있다(Baumeister \& Leary, 1995).

이와 같이 학습동기는 개인의 심리적 요인과 함께 관계성과 관련한 환경적 요인의 영향을 받 고 있으며, 학업에 영향을 미치는 정의적 요인이다. 자기결정성이론에서 설명하는 관계성에 대 한 욕구란 자신이 타인과 연결되어 있다고 느끼는 것을 말하는데, 자신이 타인에 대한 관심을 가지고 있고 타인도 자신을 배려한다고 느끼며 자신과 타인이 소속된 사회 내에서의 연결성을 가질 때 충족되는 욕구이다(Ryan \& Deci, 2000).

교수자 요인과 학습동기를 설명하는 선행연구들을 살펴보면, 교수자의 긍정적인 태도는 학습 자의 동기에 긍정적인 역할을 한다(Brigham, Scruggs, \& Masyropieri, 1992; McKinney, Robertson, Gilmore, Ford, \& Larkins, 1984; Patrick et al., 2000). 학습자는 교수자가 자신들의 흥미, 목표, 가치와의 관련성 촉진하기 위해 노력하며 선택권을 제공하고 비판적 사고를 허용하 고 독립적 사고를 지지한다고 지각할 때 그들의 동기는 향상된다(Assor, Kaplan, \& Roth, 2002; Shin, 2008). 특히 교수-학습활동 중의 교수자의 열정과 자율성 지지는 학습자를 학습활동에 참 여하게 하여 학습자의 동기에 긍정적인 영향을 미친다(김종렬, 2012; 김현진, 정재학, 2011; 이숙 정, 2006; 이윤정, 2004; Kunter et al., 2008; Lau \& Mie, 2008),

학교현장에서 교수자 변인과 학습자의 학습동기를 다룬 연구들도 주로 초·중등학교를 중심으 로 이루어져 왔고, 주로 교수자의 지지, 행동이나 태도, 신뢰가 학습동기에 영향이 있다고 보고 하고 있다. 교사-학생의 관계와 학습동기의 관계를 연구하는 학자들(Skinner \& Belmont, 1993; Stipek, 1998)은 학습자 개개인의 특성에 중점을 두기 보다는 학교에서 교사와 학생들 간의 관계 가 효과적인 학교교육의 중심이 되어야 한다고 주장하였다(이숙정, 2006). 교사와의 관계는 인지 적·정의적·도덕적 요인들을 포함하고 있기 때문에 교사에 대한 관계 유형에 따라 학생들의 학업 성취, 학습동기 등이 다르게 나타날 것이라고 기대할 수 있다(이숙정, 2006). Furrer와 Skinner(2003)는 아동과 부모, 교사, 또래와의 관계에 관한 연구를 통해, 의미 있는 타인과의 관 계가 학교에서의 아동의 학습동기를 증진하는 것으로 보여 진다고 보고하였다.

교수자의 지지에 대한 연구들을 살펴보면, 최윤선(2000)은 교사의 지지적 도움행동과 높은 기 대, 기회제공을 긍정적으로 지각한 아동은 학습에 대한 동기와 학업수행 능력이 향상되는 결과 
를 가져왔다고 보고하였다. 유지원과 강명희(2011)는 교수자가 학습자에게 학습내용의 필요성과 관련성을 충분히 이해시키며, 특히 자율성에 대한 지지를 해주는 교수-학습전략을 제공할 때 학 습자의 자기결정성 동기와 학습참여가 직접적으로 강화된다고 하였다.

교수자의 행동이나 태도가 학습동기에 영향을 미친다는 연구들을 살펴보면, 수업장면에서 교 수자의 행동은 학습자의 학습태도나 학습동기에 영향을 미친다는 연구(이철희, 2000), 그리고 교 수자의 행동을 긍정적으로 지각할수록 학습동기 유발에 긍정적인 영향을 준다는 연구(조광규, 1997)가 있다. 학생이 지각한 교사의 태도에 따라 학생들의 학습동기에 유의미한 차이가 있음을 보여준 정애숙(2005)의 연구, 교사의 태도가 아동의 학습동기에 영향을 미친다는 것을 밝힌 김고 은(2013)의 연구가 있다. 중·고등학생을 대상으로 교사의 신뢰를 다룬 이숙정(2006)의 연구에서 는 교사의 신뢰가 학생들의 학습동기 및 자아존중감, 그리고 학급풍토에 영향을 미치고 결과적 으로는 학업성취에 영향을 미친다는 것을 관계모형의 검증을 통해 밝혔다. 대학생을 대상으로 한 연구는 많지 않은데, 정은이와 박용한(2008)은 교수와의 친밀감이 학습동기와 정적인 관계가 있음을 밝혔고, 유지원과 강명희(2012)는 교수의 자율성 지지가 대학생의 동기를 강화하였다고 보고하였다.

다음으로 학습동기와 학업적응의 관계를 살펴보면, 학습동기는 학습자가 학업을 수행할 수 있도록 하는 원동력으로(Bandura, 1986), 학습자 특성을 나타내는 개인차 변인 가운데 학습자가 스스로 학습을 선택하고 노력을 기울이며 어려움이 있어도 끈기를 보이게 하는 기제이기 때문 에(김아영, 2002) 교수-학습 상황에서 간과해서는 안 될 요인으로 간주되고 있다(김아영, 2002; 한순미, 2004). 학습동기는 학업성취에 영향을 미치며(김명희, 하정희, 2008; 류관열, 엄우용, 최 성열, 2008; 한순미, 2004), 학교적응에도 긍정적인 영향을 미친다(김일태, 허남진, 2004; 김정화, 김언주, 2006; 임선화, 2006; 이윤옥, 2007; 정은이, 박용한, 2008; 추미애, 박아청, 2006; 함재수, 2012; Eisenberg, Spinard \& Morris, 2000). 이와 같이 학습동기는 학업적응에 매우 중요한 기능 을 하는 요인이다.

이상에서 살펴본 바와 같이 학교환경에서 교수자의 사회적 지지는 학습자의 학습동기와 학업 적응에 영향을 미치는 요인임을 알 수 있다. 또한 학습동기도 학업적응에 영향을 미치는 요인이 므로 이들 변인간의 관계를 통하여 대학생의 학업적응을 돕기 위한 구체적인 시사점을 도출하 기 위하여 각 변인간의 구조관계를 통합적으로 이해할 필요가 있다. 그러나 이 변인들 간의 구조 적 관계를 살펴본 연구는 아직 없다. 유사 연구로 사회적 지지의 하위요인으로 교사의 지지나 교사의 신뢰와 학습자의 적응과의 관계에서 학습동기나 학업적 자기효능감을 주제로 한 연구들 은 있다.

Heller, Swindle과 Dusenbury(1986)은 성장기 학생들은 자신에 대한 타인들의 평가에 민감하 기 때문에 의미 있는 타인인 교사, 부모, 친구들이 자신을 믿어준다고 지각하면 자기효능감이 
증진될 가능성이 높지만, 그렇지 않으면 자기효능감이 낮으며, 이는 학교생활적응의 주요 측면 인 학업성취에도 부정적인 영향을 미칠 수 있다고 하였다. 국내 연구에서도 사회적 지지를 많이 받은 청소년일수록 자기효능감이 높으며 이를 통해 심리적·사회적응력이 향상된다는 보고가 있 었으며(박영신, 김의철, 민병기, 2002; 임유진, 2001), 문승태와 김민배(2005)는 구조방정식을 통 하여 부모, 교사, 친구로부터 받은 사회적 지지가 자기효능감과 적응에 영향을 미치며, 사회적 지지로부터 영향을 받은 자기효능감이 적응에 영향을 미치게 되는 구조적 관계를 규명하였다. 또한 소연희(2008)는 초·중·고등학생을 대상으로 지각된 사회적 지지와 학업적 자기효능감 및 성취동기와 학업성취도의 관계모형을 설정하고 경로분석을 통하여 초·중·고등학생 집단 모두에 서 사회적 지지가 학업적 자기효능감을 통하여 학업성취도에 간접적으로 영향을 미치는 인과관 계 경로를 확인하였다. 한편, 이숙정(2006)은 교사의 신뢰가 학생들의 동기에 영향을 미치며 결 과적으로는 학업성취에 긍정적이라고 하였다. 즉, 교사는 학생들이 가족 다음으로 가장 많은 상 호작용하는 대상으로 학생들이 사회구성원이 되는데 필요한 지식, 기술, 가치, 태도 등을 학습하 는데 많은 영향을 미치게 된다. 이와 같은 결과들은 학습자에게는 사회적 지지원 중 교수자의 지지가 학습동기나 학업적응에 가장 큰 관계변인임을 뒷받침하고 있다.

따라서 본 연구에서는 대학생의 지각된 교수의 지지가 학습동기와 학업적응에 어떤 영향을 미치는지 변인간 구조적 관계를 통하여 알아보고, 교수의 지지와 학업적응의 관계에서 학습동기 가 매개역할을 하는지 규명해보고자 한다.

\section{III. 연구방법}

\section{1. 연구모형의 설정}

본 연구는 선행연구를 토대로 하여 교수의 지지가 대학생의 학업적응에 직접적인 영향을 미 치기도 하고 학습동기를 통하여 간접적으로도 영향을 미치기도 한다는 부분매개모형을 연구모 형으로 설정하였다. 그러나 한 가지 모형만을 검증한다면 잘못된 결론을 도출할 오류를 범할 수 있다. 구조모형분석에서는 이 모형보다 얻어진 자료에 더 잘 부합되는 모형이 존재할 가능성도 있고, 부합도의 차이가 없으면서도 더 간명한 모형이 설립할 가능성도 있기 때문이다. 따라서 연구모형 이외의 경합모형을 설정하여 이들의 지지여부를 확인할 필요가 있다(조선배, 1996). 따 라서 본 연구에서는 연구모형의 대안적 설명을 해주는 경쟁모형을 설정하였다. 경쟁모형은 선행 변인인 교수의 지지가 학습동기를 통하여 간접적으로만 대학생활적응에 영향을 미친다는 완전 매개모형으로 설정하였다. 


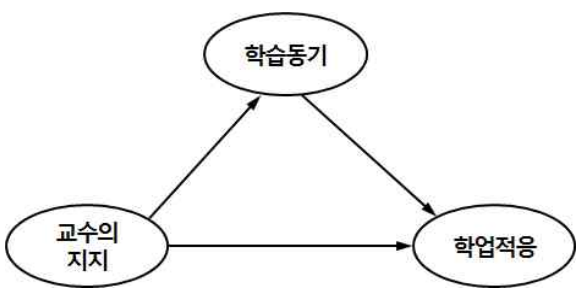

[그림 1] 연구모형(부분매개모형)

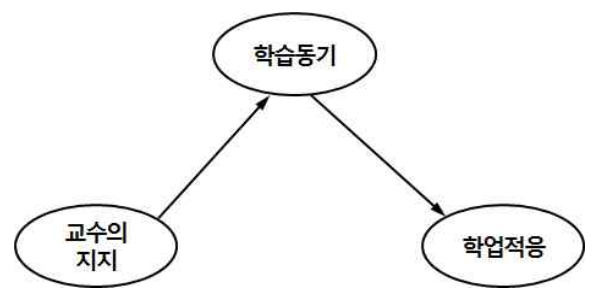

[그림 2] 경쟁모형(완전매개모형)

\section{2. 연구대상}

본 연구의 대상은 광주광역시와 전라남도에 소재한 4 개의 4 년제 대학에 재학 중인 대학생 240 명이다. 설문조사는 교양 심리학 과목의 수업시간을 통하여 실시하였으며, 실시에 앞서 본 연구 의 목적을 설명하고 동의를 구하였다. 회수된 질문지 중 무성의하거나 무응답이 많은 자료 24 부 를 제외한 216 명의 자료가 분석되었다. 연구대상의 성별분포는 남학생이 106 명 $(49.1 \%)$, 여학생 이 110 명(50.9\%)이고, 학년별 분포는 1학년 91명(42.1\%), 2학년 52명(24.1\%), 3학년 45명(20.9\%), 4 학년 28명(12.9\%)이었으며, 연구대상의 전공은 17 개 학과로, 이공계열 109 명 $(50.5 \%)$, 인문사회 계열 97 명(44.9\%), 예체능계열 10 명(4.6\%)의 순이었다.

\section{3. 측정도구 \\ 1) 교수의 지지}

본 연구에서 사용한 교수의 지지 척도는 Nolten(1994)의 사회적 지지 척도 중 교사의 지지를 측정하는 문항을 대학생에 맞도록 수정·보완한 9문항을 사용하였다. 이 척도를 대학생에게 적용 하기 위하여 심리학 전공 교수 1 인과 교육학 전공 교수 1 인이 문항내용의 타당성 검토를 한 후 5 인의 대학생을 대상으로 사전검사를 실시하여 문항내용을 최종 수정하였다. 이 척도는 4 개의 하위요인으로 를 포함한 정서적 지지 3문항(예: 교수님은 나에게 어려움이 있는지 주의 깊게 살 피신다.), 정보적 지지 2문항(예: 교수님은 내가 문제를 해결할 수 있도록 정보를 제공해주신다.), 도구적 지지 2문항(예: :교수님은 나의 목표와 관심분야에 대해 함께 이야기할 시간을 마련해 주신다.), 평가적 지지 2문항(나의 교수님은 내가 열심히 노력하거나 잘했을 때 칭찬해 주신다.) 으로 구성되어 있다. '전혀 그렇지 않다'를 1점, '별로 그렇지 않다'를 2점, '보통이다'를 3점, '대 체로 그렇다'를 4점, '매우 그렇다'를 5점으로 한 Likert식 5점 척도로 구성되어 있어서 점수가 높을수록 교수와의 관계가 우호적이고 지지적이며 만족스럽다는 것을 의미한다. 본 연구에서 산 
출한 신뢰도 계수(Cronbach's $\alpha$ )는 정서적 지지 .73, 정보적 지지 .82, 도구적 지지 .79, 평가적 지지 .80 이었으며, 전체 신뢰도 계수는 .92였다.

\section{2) 학습동기}

본 연구에서 사용한 학습동기 척도는 김아영(2002)이 개발한 학습동기검사 44 문항을 사용하 였다. 이 검사는 학업성취도를 특히 중시하는 한국의 교육현장에서 학습동기를 의미 있게 예측 할 수 있도록 학업관련 동기를 두 가지 측면에서 알아볼 수 있도록 제작된 척도로서, 학습자가 자신의 수행능력에 대해 보이는 기대나 신념을 측정하는 '학업적 자기효능감' 척도와 학습자가 자신의 실패경험에 대해 건설적인 태도로 반응하는 경향성을 측정하는 '학업적 실패내성' 척도 로 이루어진 검사이다. '전혀 그렇지 않다'를 1점, ‘별로 그렇지 않다'를 2점, '보통이다'를 3점, '대체로 그렇다'를 4점, '매우 그렇다'를 5점으로 한 Likert식 5점 척도로 구성되어 있어서 점수가 높을수록 학습동기가 높다는 것을 의미한다. 본 연구에서 산출된 신뢰도 계수는 학업적 자기효 능감 .89 , 학업적 실패내성 .81 이었으며, 전체 신뢰도 계수는 .92였다.

\section{3) 학업적응}

본 연구에서 사용한 학업적응 척도는 성선진(2010)이 개발한 학교생활적응 척도 중 학업적응 을 측정하는 18 문항을 대학생에 맞도록 수정하여 사용하였다. 이 척도는 4 개의 하위요인으로 수업참여 6 문항(예: 나는 수업시간에는 다른 생각을 하거나 장난을 치지 않고 수업에 열중한다.), 학습노력 5 문항(예: 나의 공부시간은 다른 학생들보다 더 많은 편이다.), 학습지속성 3 문항(예: 나는 공부에 열중하여 시간가는 줄 모를 때가 많다.), 학습행동통제 4 문항(예: 나는 공부가 지루 하고 재미없더라도 내가 해야 할 만큼은 다한다.)으로 구성되어 있다. '전혀 그렇지 않다'를 1점, '별로 그렇지 않다'를 2점, '보통이다'를 3점, '대체로 그렇다'를 4점, '매우 그렇다'를 5점으로 한 Likert식 5점 척도로 구성되어 있어서 점수가 높을수록 학업적응을 잘한다는 것을 의미한다. 본 연구에서 산출된 신뢰도 계수(Cronbach's $\alpha$ )는 수업참여 .78, 학습노력 .77, 학습지속성 .75, 학 습행동통제 .72였고 전체 신뢰도 계수는 .91이었다.

\section{4. 자료분석}

본 연구에서 수집한 자료는 통계 프로그램 SPSS 21.0과 AMOS 21.0을 이용하여 분석하였다. 먼저 연구대상의 일반적 배경을 알아보기 위하여 빈도와 백분율을 구하고, 본 연구에서 사용한 
측정도구의 신뢰도를 알아보기 위하여 Cronbach's $\alpha$ 를 산출하였다. 각 변인 간 상관관계를 알 아보기 위하여 Pearson의 적률상관계수를 구하였다.

다음으로 본 연구에서 설정한 연구모형을 검증하기 위해 구조방정식 모형(SEM)을 통한 분석 을 실시하였다. 본 연구에서 설정한 연구모형의 타당성을 입증하기 위하여 경쟁모형과 $\chi^{2}$ 차이 검증을 통하여 비교하였다. 구조모형의 적합도 평가를 위하여 $\chi^{2}$ 검증과 적합도 지수들 중 TLI(Tucker Lewis Index), CFI(Comparative Fit Index), RMSEA(Root Mean Square of Error Approximation)를 사용하였다. 마지막으로 매개효과의 유의미성을 검증하기 위하여 Aroian 방 정식을 활용한 Sobel 검증과 Bootstrap 절차를 사용하여 유의도를 검증하였다.

\section{IV. 연구결과}

\section{1. 측정변수들의 기술통계 및 상관분석}

측정변수들의 기술통계 및 상관분석을 실시한 결과는 <표 $1>$ 과 같다. 학업적응의 하위요인인 학 습노력을 제외한 모든 측정변수들의 평균점수가 5점 척도 하에서 3점을 상회하는 것으로 나타나 중립점수인 '보통이다'보다 약간 더 긍정적인 방향을 보였다. 측정변수들 중 정보적 지지 $(\mathrm{M}=3.36$, $\mathrm{SD}=.76)$ 와 자기효능감 $(\mathrm{M}=3.30, \mathrm{SD}=.49)$ 이 다른 측정변수들에 비해 높은 평균점수를 보였다.

<표 1> 측정변수들 간의 상관관계 및 기술통계

\begin{tabular}{lllllllllll}
\hline \multicolumn{1}{c}{ 변인 } & 1 & 2 & 3 & 4 & 5 & 6 & 7 & 8 & 9 & 10 \\
\hline 1. 정서적 지지 & 1 & & & & & & & & & \\
2. 정보적 지지 & $.76^{* *}$ & 1 & & & & & & & & \\
3. 도구적 지지 & $.72^{* *}$ & $.73^{* *}$ & 1 & & & & & & & \\
4. 평가적 지지 & $.65^{* *}$ & $.64^{* *}$ & $.71^{* *}$ & 1 & & & & & & \\
5. 자기효능감 & $.25^{* *}$ & $.26^{* *}$ & $.20^{* *}$ & $.23^{* *}$ & 1 & & & & & \\
6. 실패내성 & $.33^{* *}$ & $.32^{* *}$ & $.30^{* *}$ & $.25^{* *}$ & $.73^{* *}$ & 1 & & & & \\
7. 수업참여 & $.33^{* *}$ & $.28^{* *}$ & $.25^{* *}$ & $.28^{* *}$ & $.63^{* *}$ & $.42^{* *}$ & 1 & & & \\
8. 학습노력 & $.28^{* *}$ & $.23^{* *}$ & $.25^{* *}$ & $.24^{* *}$ & $.46^{* *}$ & $.36^{* *}$ & $.63^{* *}$ & 1 & & \\
9. 학습지속성 & $.23^{* *}$ & $.19^{* *}$ & $.16^{*}$ & $.20^{* *}$ & $.56^{* *}$ & $.38^{* *}$ & $.67^{* *}$ & $.68^{* *}$ & 1 & \\
10. 학습행동통제 & $.20^{* *}$ & $.22^{* *}$ & $.14^{*}$ & $.21^{* *}$ & $.60^{* *}$ & $.42^{* *}$ & $.55^{* *}$ & $.47^{* *}$ & $.63^{* *}$ & 1 \\
\hline $\mathrm{M}$ & 3.05 & 3.36 & 3.05 & 3.17 & 3.30 & 3.00 & 3.20 & 2.68 & 3.05 & 3.16 \\
\hline $\mathrm{SD}$ & .77 & .76 & .90 & .89 & .49 & .49 & .61 & .71 & .80 & .55 \\
\hline 왜도 & -.08 & -.32 & .11 & -.25 & .24 & .01 & -.07 & .38 & .20 & -.03 \\
\hline 첨도 & .15 & .37 & -.35 & -.02 & .93 & .39 & .75 & .93 & .16 & -.16 \\
\hline
\end{tabular}

$p<.05,{ }^{* * *} p<.01,{ }^{* * *} p<.001$ 
상관분석 결과를 살펴보면, 교수의 지지 하위요인들은 모두 학습동기 및 학업적응의 하위요인 들과 유의미한 정적 상관을 보였다. 학습동기 하위요인인 자기효능감과 실패내성도 모두 학업적 응의 하위요인들과 유의미한 정적 상관을 보였다. 따라서 교수의 지지가 학습동기와 학업적응에 긍정적인 영향을 미치고, 학습동기도 학업적응에 긍정적인 영향을 미칠 수 있음을 알 수 있다.

또한 <표 2>에 제시한 바와 같이 각 잠재변수에서 관측변수로 가는 모든 경로의 표준화된 요인부하량이 .5 이상의 값을 보이고 있으므로(우종필, 2012) 통계적으로 유의미한 것으로 나타 나 문항의 집중타당성이 입증되었다.

<표 2> 잠재변인별 확인적 요인분석

\begin{tabular}{cccccc}
\hline 잠재변수 & 측정변수 & $B$ & $\beta$ & S.E. & C.R. \\
\hline \multirow{3}{*}{ 교수의 지지 } & 정서적지지 & 1 & .861 & & \\
& 정보적지지 & .979 & .857 & .061 & $15.961^{* * *}$ \\
& 도구적지지 & 1.152 & .856 & .075 & $15.359^{* * *}$ \\
& 평가적지지 & 1.035 & .775 & .078 & $13.250^{* * *}$ \\
\hline \multirow{2}{*}{ 학습동기 } & 자기효능감 & 1 & .990 & & \\
& 실패내성 & .716 & .720 & .074 & $9.741^{* * *}$ \\
\hline \multirow{3}{*}{ 학업적응 } & 수업참여 & 1 & .824 & & \\
& 학습노력 & 1.057 & .745 & .090 & $11.718^{* * *}$ \\
& 학습지속성 & 1.340 & .837 & .102 & $13.188^{* * *}$ \\
& 학습행동통제 & .779 & .715 & .071 & $10.926^{* * *}$ \\
\hline
\end{tabular}

${ }^{*} p<.05,{ }^{* *} p<.01,{ }^{* * *} p<.001$

\section{2. 구조모형의 검증}

교수의 지지와 학습동기, 학업적응간의 영향력을 알아보기 위하여 선행연구를 토대로 설정한 연구모형이 수집된 자료에 일치하는지를 분석하였다. 일반적으로 측정된 변수들의 왜도 (skewness)가 -2보다 작거나 2보다 클 때 정규분포의 가정을 위반한 것으로 보는데, 본 연구에서 측정된 변수들의 첨도(kurtosis)와 왜도가 모두 2 이하로서 정규분포를 하고 있어서 최대우도법 (Maximum Likehood Method)을 사용하여 구조모형의 적합도를 검증하였다. 교수의 지지를 예 언변수로, 학습동기를 매개변수로, 학업적응을 결과변수로 설정한 부분매개모형과 완전매개모 형의 적합도를 분석한 결과는 <표 $2>$ 와 같다. 부분매개모형의 $\chi^{2}$ 값은 73.842 , 완전매개모형의 $\chi^{2}$ 값은 80.239였으며 각각 $p<.001$ 수준에서 유의미하였다. 그러나 $\chi^{2}$ 값은 표본의 크기에 심하 게 영향을 받기 때문에(Bentler \& Bonett, 1980) $\chi^{2}$ 값을 자유도로 나눈 값인 $\chi^{2} / d f$ 아 5보다 작은 경우 적합한 것으로 가정하였고(Kelloway, 1998), $\chi^{2}$ 값을 검정통계량으로 간주하지 않고 모형 의 양호도의 척도로서만 간주하였다. 
비교 적합도 지수인 $\mathrm{TLI}$ 와 $\mathrm{CFI}$ 의 값은 .95 이상일 때 아주 좋은 적합도, .90 이상이면 좋은 적합도로 간주한다. 모수 불일치성 지수인 RMSEA는 값이 작을수록 좋은 적합도로 해석하는데 .05보다 작으면 좋은 적합도, .08보다 작으면 괜찮은 적합도, .10보다 작으면 보통의 적합도, .10 보다 크면 나쁜 적합도로 해석한다(홍세희, 2000). <표 3>에 제시된 바와 같이 본 연구의 연구모 형인 부분매개모형이 경쟁모형인 완전매개모형보다 적합도가 모든 지수에서 더 좋은 것으로 나 타나서 학습동기를 부분적으로 매개하는 연구모형이 더 적합함을 보여주고 있다.

본 연구에서 설정한 연구모형의 타당성을 입증하기 위하여 경쟁모형과 $\chi^{2}$ 차이검증을 통하 여 비교하였다. $\chi^{2}$ 차이가 자유도 1 일 때 임계값인 3.84 보다 크면 부분매개모형을 적합한 모형 으로 채택하고 3.84보다 작으면 더 간명한 모형인 완전매개모형을 채택한다(김계수, 2002). 두 모형간의 $\chi^{2}$ 값의 차이가 6.397로 임계값인 3.84 보다 커서 부분매개모형을 더 적합한 모형으로 채택하였다.

<표 3> 연구모형과 경쟁모형의 적합도 지수

\begin{tabular}{lccccc}
\hline \multicolumn{1}{c}{ 구조모형 } & $\chi^{2}$ & $d f$ & TLI & CFI & RMSEA \\
\hline 부분매개모형 & $73.842^{* * *}$ & 32 & .954 & .967 & .078 \\
완전매개모형 & $80.239^{* * *}$ & 33 & .949 & .963 & .082 \\
\hline 차이 & 6.397 & 1 & & & \\
\hline${ }^{*} p<.05,{ }^{* *} p<.01,{ }^{* * *} p<.001$ &
\end{tabular}

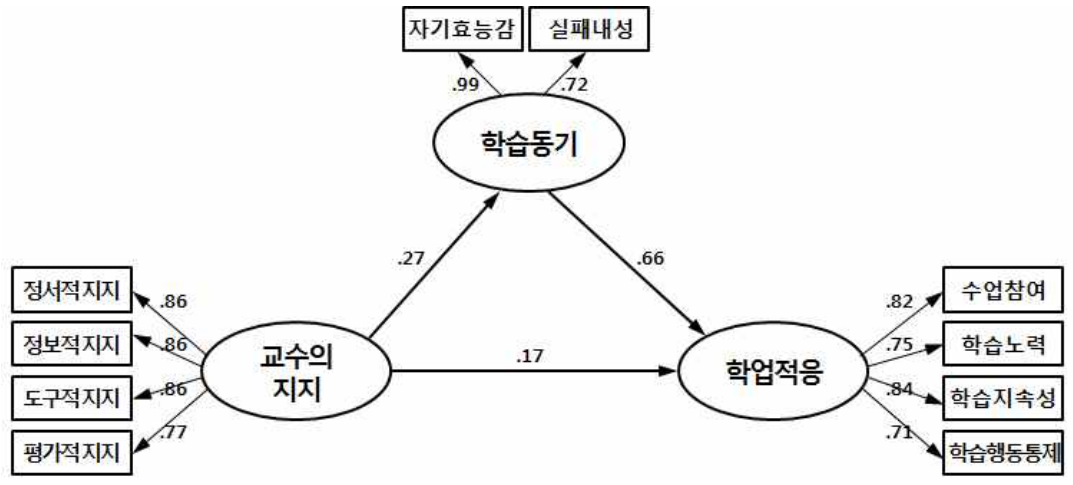

[그림 3] 연구모형의 표준화 구조계수

교수의 지지와 학습동기, 학업적응 간의 경로계수의 유의도를 검증한 결과는 <표 $4>$ 와 같다. (교수의 지지 $\rightarrow$ 학습동기), (교수의 지지 $\rightarrow$ 학업적응), (학습동기 $\rightarrow$ 학업적응)의 경로계수가 모두 유의미한 것으로 나타났다. 즉, 교수의 지지가 높을수록 대학생의 학습동기가 높고, 학습동 기가 높을수록 학업적응을 더 잘하는 것으로 나타났다. 또한 교수의 지지가 높을수록 학업적응 
수준도 높은 것으로 나타났다.

<표 4> 연구모형의 경로계수

\begin{tabular}{lcccc}
\hline 경로 & $B$ & $\beta$ & S.E. & C.R. \\
\hline 학습동기 $\leftarrow$ 교수의 지지 & .197 & .268 & .051 & $3.870^{* * *}$ \\
\hline 학업적응 $\leftarrow$ 교수의 지지 & .125 & .167 & .046 & $2.745^{* *}$ \\
학업적응 $\leftarrow$ 학습동기 & .679 & .665 & .084 & $8.106^{* * *}$ \\
\hline
\end{tabular}

" $p<.05,{ }^{* * *} p<.01,{ }^{* * * * *} p<.001$

교수의 지지와 학업적응의 관계에서 학습동기의 매개효과의 유의미성을 검증하기 위하여 Sobel 검증을 실시하였다. 계산공식은 다음과 같다.

$$
Z_{a b}=\frac{a b}{\sqrt{S E_{a}^{2} S E_{b}^{2}+b^{2} S E_{a}^{2}+a^{2} S E_{b}^{2}}}
$$

위 식에서 $a$ 는 '교수의 지지 $\rightarrow$ 학습동기'의 비표준화계수의 값, $b$ 는 '학습동기 $\rightarrow$ 학업적응'의 비 표준화계수의 값을 의미한다. $S E$ 는 표준오차를 나타내는데 $S E a$ 는 $a$ 의 표준오차 값, $S E b$ 는 $b$ 의 표준오차 값을 의미한다. <표 $4>$ 에 제시된 $a$ 와 $b$ 의 추정치를 이용하여 계산한 결과, 매개효과가 통계적으로 유의미한 것으로 나타났다 $(Z=3.485, \mathrm{p}<.001)$. 이 결과를 통하여 학습동기는 교수의 지지와 학업적응 간의 관계를 부분적으로 매개한다고 할 수 있다.

위의 Sobel 검증은 정규분포를 가정하고 있고 \pm 1.96 을 기준으로 매개효과를 검증한다. 그러나 이러한 가정에서 자유롭고 다변량 정규성을 벗어난 데이터 분석에 유용하게 사용되는 Bootstrapping을 이용하여 매개효과의 유의미성을 검증하였으며, 그 결과는 <표 5>와 같다. 교 수의 지지와 학업적응의 관계에서 학습동기의 매개효과는 95\% 구간에 BC(.046 .284)가 0을 포 함하지 않아 유의미하게 나타났다 $\beta=.178, \mathrm{p}<.001)$.

마지막으로 최종모형의 다중상관치(squared multiple correlation; SMC)를 살펴본 결과, 학습 동기는 .07, 학업적응은 .53 으로 나타났다. 따라서 교수의 지지가 학습동기를 설명하는 변량은 $7 \%$, 학업적응을 설명하는 변량은 $53 \%$ 인 것으로 나타나 교수의 지지는 학습동기보다 학업적응 에 더 많은 영향을 주는 것으로 나타났다. 
<표 5> 예측변수의 효과계수

\begin{tabular}{|c|c|c|c|c|c|c|}
\hline \multirow{2}{*}{ 경로 } & 직접효과 & & 간접효과 & & 총효과 & \multirow{2}{*}{$\mathrm{SMC}$} \\
\hline & $\beta \quad(\mathrm{BC} 95 \% \mathrm{CI})$ & $\beta$ & $(\mathrm{BC} 95 \% \mathrm{CI})$ & $\beta$ & (BC 95\% CI) & \\
\hline 학습동기 $\leftarrow$ 교수의 지지 & $.268^{* * * *}(.077, .438)$ & & - & $.268^{* * *}$ & $(.077, .438)$ & .07 \\
\hline 학업적응 $\leftarrow$ 교수의 지지 & $.167^{* *} \quad(.043, .320)$ & $.178^{* * * *}$ & $(.046, .284)$ & $.345^{* * *}$ & $(.192, .479)$ & .53 \\
\hline 학업적응 $\leftarrow$ 학습동기 & $.665^{* * *}(.546, .773)$ & & - & $.665^{* * *}$ & $(.546, .773)$ & \\
\hline
\end{tabular}

$p<.05,{ }^{* *} p<.01,{ }^{* * *} p<.001$, Boostrap $=500, \mathrm{BC}=$ Bais-Corrected, 추정치는 표준화계수임

\section{$\mathrm{V}$. 논의 및 결론}

본 연구는 대학생이 지각한 교수의 지지와 학습동기 및 학업적응의 관련성을 알아보고, 관련 변인들 간의 구조적 인과모형을 탐색하였다. 연구모형에 기초하여 교수의 지지가 학습동기와 학 업적응에 어떤 영향을 미치는지 분석한 후 교수의 지지와 학업적응의 관계를 학습동기가 어느 정도 매개하는지 검증하였다. 이를 통하여 대학생의 학습지도를 위한 기초자료와 학습동기의 향 상을 위한 교수자의 역할에 대한 시사점을 얻고자 하였다. 본 연구에서 얻어진 결과를 토대로 하여 논의하면 다음과 같다.

첫째, 교수의 지지의 모든 하위요인들은 학업적응의 모든 하위요인들과 유의미한 상관을 보 였으며, 모든 하위요인에서 정적 상관을 보여서 교수의 지지에 대한 지각이 높을수록 학업적응 도가 높은 것으로 나타났다. 이는 교수와의 친밀감이나 개방성이 대학생의 학업적응을 예측한다 고 한 정은이와 박용한(2008)의 연구와 부분적으로 일치하며, 교수자의 지지가 학교생활의 흥미, 학업성취도 등에 영향을 미친다는 연구들(정규석, 2004; 정은이, 박용한, 2008; 최지은, 신용주, 2003; Rosenfeld, Richman, \& Bowen, 2000)과도 맥락을 같이 하였다. 이 연구의 결과를 통하여 교수의 지지는 학업적응 전반에 영향력이 있는 변인임을 시사하였다.

둘째, 교수의 지지의 모든 하위요인들은 학습동기의 하위요인들과 유의미한 상관을 보였으며, 모든 하위요인에서 정적 상관을 보여서 교수의 지지에 대한 지각이 높을수록 학습동기가 높은 것으로 나타났다. 이는 교수와의 친밀감이 대학생의 학습동기와 정적인 관계가 있음을 밝힌 정 은이와 박용한(2008)의 연구, 교수의 자율성 지지가 대학생의 동기를 강화한다고 한 유지원과 강명희(2012)의 연구결과와 부분적으로 일치한다. 그리고 교수자의 지지적 행동이 학습동기에 영향을 미친다고 한 기존의 연구들(김종렬, 2012; 김현진, 정재학, 2011; 유지원, 강명희, 2011; 이숙정, 2006; 이윤정, 2004; 최윤선, 2000; Kunter et al., 2008; Lau \& Mie, 2008)과도 일치하는 것으로 교수의 지지는 학습동기에 영향력이 있는 변인임을 시사하였다. 
셋째, 학습동기의 모든 하위요인들은 학업적응의 하위요인들과 유의미한 상관을 보였으며, 모 든 하위요인에서 정적 상관을 보여서 학습동기가 높을수록 학업적응도가 높은 것으로 나타났다. 이는 학습동기는 학업성취(김명희, 하정희, 2008; 류관열, 엄우용, 최성열, 2008; 한순미, 2004)와 학교적응(김일태, 허남진, 2004; 임선화, 2006; 정은이, 박용한, 2008; 추미애, 박아청, 2006; 함재 수, 2012; Eisenberg, Spinard, \& Morris, 2000)에 영향력 있는 변인임을 밝힌 기존의 연구들과 일치하는 결과로, 학습동기는 학업적응에 매우 영향력이 있는 변인임을 시사하였다.

넷째, 교수의 지지와 학습동기, 학업적응 간 구조적 인과모형을 설정하고 경로계수의 유의도 를 검증한 결과, 모든 경로가 유의미한 것으로 나타났으며, 교수의 지지와 학업적응의 관계에서 학습동기가 부분매개자 역할을 하는 것으로 나타났다. 즉, 교수의 지지, 학습동기, 학업적응은 긴밀한 관계가 있으며, 교수의 지지는 학업적응에 직접적인 영향을 미치기도 하지만 학습동기를 향상시켜서 학업적응에 간접적으로도 영향을 미친다는 것이다. 이러한 결과는 사회적 지지를 많 이 받을수록 자기효능감이 높으며 이를 통해 심리적·사회적응력이 향상된다는 연구들과 부분적 으로 일치하며(문승태, 김민배, 2005; 박영신, 김의철, 민병기, 2002; 소연희, 2008; 임유진, 2001), 교사의 신뢰가 학생들의 동기에 영향을 미치며 결과적으로는 학업성취에 긍정적이라고 한 이숙 정(2006)의 연구와 그 맥락을 같이 한다.

본 연구의 시사점은 다음과 같다. 학업적응에는 학습동기가 중요한 역할을 하는데 교수의 지 지와 학습동기 및 학업적응 간의 위계적인 관계를 고려하여 학습동기 향상에 기여할 수 있는 교수와의 긍정적인 상호작용의 기회를 제공하는 프로그램들이 계발되어야 한다. 왜냐 하면 대학 에서의 교수-학생 간 상호작용은 정기적이고 빈번하게 이루어지지 않고 초·중등학교의 교사-학 생간의 관계와는 다른 상호작용 방식으로 인해 전반적인 학교생활의 적응에 어려움을 느끼기 때문이다(정은이, 박용한, 2008). 수업시간에는 교수자와 학습자 간 상호작용의 기회를 가질 수 있도록 하는 수업설계가 이루어져야 할 것이며, 연구 결과에도 나타난 바와 같이 교수의 지지 하위요인 중 특히 교수의 정서적 지지가 학습동기뿐만 아니라 학업적응과 관련성이 상대적으로 높기 때문에 교수자와 긍정적인 상호작용의 기회를 제공해야 한다. 특히 학습자들이 성공에 대 한 긍정적인 기대감을 갖도록 학습 난이도를 구성하고, 학습자가 수업에 직접 참여할 수 있는 기회를 많이 제공하여 상호작용의 기회를 많이 갖도록 하며, 성공에 대한 의미 있는 강화를 통하 여 교수-학생 간 정서적으로 가까운 친밀감을 형성하는 것이 학습동기의 향상과 학업적응에 긍 정적인 역할을 할 것이다.

또한 수업시간 이외의 시간에도 교수와 학생 간 상호작용을 할 수 있는 비정규 교육과정의 개발 및 확대가 필요하다. 정규 수업시간 이외에 교수-학생 간 만남의 기회을 확대하여 개별면담 이나 소그룹 면담을 통한 지도, 교수와 학생이 함께 참여하는 다양한 공동체 프로그램을 확대하 여 학문 이외의 활동을 통한 사제 간의 사적인 만남 등을 통하여 교수-학생 간 인간적인 신뢰를 
구축하기 위한 활동을 할 수 있는 여건이 조성되어야 한다. 이를 위해서는 대학의 교수는 학생들 에게 교수자의 역할뿐만 아니라 촉진자, 상담자, 조력자로서의 역할을 제공할 수 있는 적극적인 자세와 노력이 필요하며, 이를 뒷받침하기 위한 대학의 행정적 재정적 지원도 필요하다.

본 연구가 교수의 지지와 학습동기 및 학업적응의 관계를 탐색하고 교수의 지지가 대학생의 학습동기 향상과 학업적응에 대한 영향력 및 학습동기의 매개효과를 검증하였다는 점에서 의의 가 있으나 몇 가지 제한점이 있다. 본 연구의 제한점과 향후 연구를 위한 제언을 하면 다음과 같다. 첫째, 본 연구의 대상이 광주·전남지역에 소재한 대학에 재학 중인 대학생을 편의표집에 의해 실시하였기 때문에 대상자의 특성이 확대 또는 축소되었을 가능성이 있다. 따라서 이 결과 를 일반화하여 해석하는데 한계가 존재한다. 둘째, 본 연구는 대학생의 학교 환경변인인 교수의 지지와 학습자의 정의적 변인인 학습동기만을 선정하여 학업적응에 직·간접적 영향력을 살폈다. 이 요인들이 학업적응에 영향을 미치는 중요한 변수이기는 하나, 성별, 학년별, 가정환경별 요인 등 다양한 인구통계학적 특성을 포괄한 차이를 검증해보는 것도 좋은 주제가 될 것으로 본다. 셋째, 본 연구의 결과를 대학교육의 현장에서 보다 의미 있게 일반화하기 위해서는 초·중등학생 집단과의 차이 검증을 통한 비교분석도 의미가 있을 것으로 본다.

본 연구의 결과는 대학생의 학업적응력을 향상시키기 위해서는 교수의 지지를 통한 학습자의 학습동기를 향상시키는 것이 매우 중요함을 시사하며, 이를 토대로 대학생의 학업적응과 더 나아 가 학교생활적응력을 높이기 위한 상담 및 학생지도에 필요한 시사점을 제공한다고 할 수 있다. 


\section{참고문헌}

권재환, 이성주(2013). 대학생의 지각된 부모양육태도가 자기통제력과 학교생활적응에 미치는 영향: 자기통제력의 매개효과 검증. 한국청소년연구, 24(2), 35-62.

김계수(2002). AMOS 구조방정식 모형분석. 서울: SPSS 아카데미.

김고은(2013). 초등학생이 지각한 담임교사의 태도가 학교생활 적응과 학습동기 및 친구관계에

미치는 영향. 석사학위 논문, 한양대학교.

김명희, 하정희(2008). 학습동기와 학습기술이 학업성취 및 학교적응에 미치는 영향: 초등학생과 중학생 중심으로. 아동교육, 17(2), 33-48.

김선연, 신효진(2012). 대학생의 학과교수 만족도 구성요인 타당화 및 학업성취도와의 관계 분

석. 한국교원교육연구, 29(1), 207-226.

김성경(2003). 대학 신입생의 스트레스와 학교적응에 관한 연구. 청소년학연구, 10(2), 215-237. 김아영(2002). 학업동기 척도 표준화 연구. 교육평가연구, 15(1), 157-184.

김연수(1995). 정신장애인의 삶의 만족도와 사회적 지지도에 관한 연구. 석사학위 논문, 공주대 학교.

김일태, 허남진(2004). 비학업자아개념과 학습동기 및 학교적응간의 관계 분석. 열린교육연구, 12(1), 75-96.

김정화, 김언주(2006). 아동이 지각한 교사신뢰 및 학습동기와 학교생활적응간의 관계. 아동교육 연구, 15(2), 117-129.

김종렬(2012). 부모의 교사의 자율적지지, 내재적 미래목표와 수업참여간의 구조적 관계분석. 초 등교육연구, 25(1), 147-167.

김현진, 정재학(2011). 지각된 교수자 특성과 대학생들의 학업적 흥미, 즐거움, 내재동기, 인지적

학습전략 사용 및 과목만족도의 관계 분석. 교육심리연구, 25(3), 569-589.

노충래(2002). 재외국민특례입학생의 대학생활적응에 관한 연구-스트레스, 자긍심, 삶의 만족도

및 대학환경인식의 관계와 서비스욕구를 중심으로. 정신보건과 사회사업, $13,87-120$. 류관열, 엄우용, 최성열(2008). 중·고등학생의 학업적 자기효능감, 타인기대와 학업성취도 관계 에서 자기조절학습전략의 효과. 교육심리연구, 24(3), 661-685.

문승태, 김민배(2005). 농업게 고등학생들의 사회적 지지, 자기효능감 및 적응 간의 구조방정식

분석. 농업교육과 인적자원개발, 37(2), 37-55.

문은식, 김충희(2002). 청소년의 학교생활 적응행동에 영향을 미치는 사회·심리적 변인들의 구조 적 분석. 교육심리연구, 16(2), 219-241. 
박영신, 김의철, 민병기(2002). 부모의 사회적 지원, 청소년의 자기효능감과 생활 만족도 변화에 대한 종단자료 분석과 생활 만족도 형성에 대한 구조적 관계 분석. 교육심리연구, 16(2), 63-92.

박희자(2003). 초등학생이 지각한 교사 및 부모의 태도와 학교적응간의 관계. 석사학위 논문, 창 원대학교.

봉미미, 황아름, 송주연(2010). 학생들의 자기효능감과 성취목표 형성에 영향을 미치는 교사의 말과 행동. 교육방법연구, 22(1), 167-193.

성선진(2010). 청소년의 학교생활 적응 관련요인의 인과적 관계분석. 박사학위 논문, 충북대학교. 소연희(2008). 학교 급별에 따른 지각된 사회적 지지, 학업적 자기효능감 및 성취동기 및 학업성

취도와의 관계: 경로모형을 중심으로. 아동교육, 17(2), 49-64.

우성희(2011). 청소년의 학교적응에 영향을 미치는 변인들 간의 구조적 관계. 석사학위 논문, 경 북대학교.

유지원, 강명희(2012). 대학생의 학습참여에 영향을 미치는 수업환경과 학습자 요인 간의 구조적 관계. 학습자중심교과교육연구, 12(4), 309-337.

윤소정, 주자현, 이은영(2013). 청소년이 지각한 사회적지지 체계와 학급응집력 및 학교적응과의

관계. 열린교육연구, 21(2), 185-207.

윤주(2001). 학교 홈페이지 활용에 따른 교사-학생간의 친밀감과 신뢰감의 발달. 석사학위 논문, 연세대학교.

옥경희(2001). 대학생들의 사회적 지지와 대학생활 적응. 학생생활연구, 8, 21-39.

우종필(2012). 구조방정식모텔 개념과 이해. 서울: 한나래.

이경림, 박재국(2007). 장애대학생의 대학생활적응 실태 및 사회적 지지에 대한 인식. 특수아동 교육연구, 9(1), 289-308.

이경아, 정현희(1999). 스트레스, 자아존중감 및 교사와의 관계가 청소년의 학교적응에 미치는 영향, 한국심리학회지, 11(2), 213-226.

이수진(2009). 대학생이 지각하는 사회유대감과 자율성이 학교생활적응과 주관적 안녕감에 미치

는 영향: 대인관계문제를 매개로. 한국심리학회지: 학교, 6(2), 229-248.

이숙정(2006). 중·고생의 교사신뢰와 자아존중감, 학습동기, 학업성취 및 학급풍토간의 관계모형 검증. 교육심리연구, 20(1), 197-218.

이윤옥(2007). 중학생의 학교생활적응과 학업동기와의 관계. 교육논총, 27(2), 87-119.

이윤정(2004). 초등학교의 교사에 대한 친밀감과 학교 적응의 관계. 석사학위 논문, 서울교육대 학교.

이철희(2000). 아동이 지각한 교사의 행동이 학습동기에 미치는 영향. 석사학위 논문, 관동대학교. 임선화(2006). 학업적 자아개념, 학습동기, 자기주도적 학습능력이 학교적응의 예측력에 미치는 
영향. 박사학위 논문, 관동대학교.

임유진(2001). 청소년이 지각한 사회적 지지와 자기효능감 및 학교생활 적응간의 관계. 석사학위

논문, 전북대학교.

장경문(2005). 중학생이 지각한 사회적지지 및 자기통제력이 학교스트레스와 적응에 미치는 영

향, 청소년학연구, 12(1), 1-16.

정규석(2004). 사회적 관계요인이 청소년의 학교적응에 미치는 영향. 한국사회복지학, 56(1), 235-252

정여주, 홍성례(2012). 대학생의 자기효능감과 주관적 삶의 질 관계 연구: 학교생활만족도와 관 계만족도의 매개효과를 중심으로. 청소년복지연구, 14(3), 239-257.

정애숙(2005). 학생이 지각한 교사의 태도가 학생의 학습동기 및 학교적응에 미치는 영향. 석사 학위 논문, 전남대학교.

정은이, 박용한(2008). 대학생들의 교수신뢰와 학습동기 및 대학생활적응과의 관계, 아시아교육 연구, 9(1), 73-93.

조광규(1997). 교사행동에 대한 학생의 지각이 학습동기 및 학업성취에 미치는 영향. 석사학위 논문, 전남대학교.

조선배(1996). LISREL 구조방정식 모델. 영지문화사.

최윤선(2000). 아동이 지각한 교사행동과 자아존중감 및 학습동기간의 관계연구. 석사학위 논문, 숙명여자대학교.

최지은, 신용주(2003). 청소년이 지각한 부모-자녀 관계, 또래 관계, 교사와의 관계가 학교생활 적응에 미치는 영향. 대한가정학회지, 41(2), 1-12.

추미애, 박아청(2006). 초등학생의 자기효능감과 학습동기 및 학교적응간의 관계. 아동교육, 15(2), 271-288.

하정희, 정은선, 송수민 (2010). 지각된 부모의 양육태도가 자녀의 성취목표지향성에 미치는 영

향: 강인성의 매개역할. 상담학연구, 11(4), 1375-1392.

한순미(2004). 학습동기 변인들과 인지전략 및 학업성취간의 관계. 교육심리연구, 18(1), 229-350. 함재수(2012). 중고등학생들의 학교학습동기, 학업적 효능감, 귀인성향이 학교적응에 미치는 영 향. 박사학위 논문, 관동대학교.

홍세희(2000). 구조방정식 모형의 적합도 지수 선정기준과 그 근거. 한국심리학회지: 임상, 19(1), 161-177.

Alva, S. A. (1991). Academic vulnerability among Mexican-American students: The importance of protective resource and appraisals. Hispanic Journal of Behavioral Sciences, 13, 18-34.

Bandura, A. (1977). Self-efficacy: Toward a unifying theory of behavior change. Psychological 
Review, 84, 191-215.

Bandura, A. (1986). Social foundations of thought and action: A social cognitive theory. Englewood Cliffs, NJ: Prentice Hall.

Baumeister, R. F. \& Leary, M. R. (1995). The need to belong: Desire for interpersonal attachments as a fundamental human motivation. Psychological Bulletin, 117, 497-529.

Brigham, F. J., Scruggs, T. E., \& Mastropieri, M. A. (1992). Teacher enthusiasm in learning disabilities classrooms: Effects on learning and beavior. Learning Disability Research \& Practice, $7,68-73$.

Chien-Huey Chang, S., \& Schaller, J. (2000). Perspectives of adolescents with visual impairments on social support from their parents. Journal of Visual Impairment \& Blindness, 94, 69-84.

Clark, M. L. (1991). Social identity, peer relations, and academic competence of African-American adolescents. Education and Urban Society, 24, 41-52.

Cutrona, C. E., Cole, V., Colangelo, N., Assouline, S. G., \& Russell, D. W. (1994). Perceived parental social support and academic achievement: An attachment theory perspective. Journal of Personality and Social Psychology, 66, 369-378.

Deci, E. L., \& Ryan, R. M. (1985). Intrinsic motivation and self-determination in human behavior. New York: Plenum.

Dubow, E. F., \& Tisak, J. (1989). The relation between stressful life events and adjustment in elementary school children: The role of social support and social problem-solving skills. Child Development, 60, 1412-1413.

Dubow, E. F., Tisak, J., Causey, D., \& Hryshko, A. (1991). A two-year longitudinal study of stressful life event, social support, and social problem-solving skills: Contributions to children's behavioral and academic adjustment. Child Development, 62, 583-599.

Efklides, A. (2001). Metacognitive experiences in problem solving: Metacognition, motivation, and self-regulation. In A. Efklides, J. Kuhl, \& R. M. Sorrentino (Eds.), Trends and prospects in motivation research (pp. 297-323). Dordrecht, The Netherlands: Kluwer.

Efklides, A., \& Volet, S. (2005). Emotional experiences during learning: Multiple situated and dynamic. Learning \& Instruction, 15(5), 501-519.

Eisenberg, N., Spinard, T. L., \& Morris, A. S., (2002). Regulation, resiliency, and quality of social functioning. Self and Identity, 1, 121-128.

Ford, J., \& Sutphen, R. D. (1996). Early intervention to improve attendance in elementary schoolfor at-risk children: A pilot program. Social Work in Education, 18, 95-102. 
Furrer, C., \& Skinner, E. (2003). Sense of Relatedness as a factor in children's academic engagement and performance. Journal of Educational Psychology, 95(1), 148-162.

Furstenberg Jr., F. F., Rumbaut, R. G., \& Settersten Jr., R. A. (2005). On the frontier of adulthood: Emerging themes and new directions. In R. A. Settersten Jr., F. F. Furstenberg Jr., R. G. Rumbaut (Eds.), On the frontier of adulthood: Theory, research, and public policy. Chicago: The University of Chicago Press.

Ghaith, G. M. (2002). The relationship between cooperative learning, preception of social support, and academic achievement. System, 30, 263-273.

Goldsmith, D., \& Albrecht, T. L. (1993). The impact of supportive communication networkson test anxiety and performance. Communication Education, 42, 142-158.

Heller, K., Swindle, R. W., \& Dusenbury, L. (1986). Component social support processes: Comments and integration. Journal of Consulting and Clinical Psychology, 54, 466-470.

Kef, S. (1997). The personal networks and social supports of blind an visually impaired adolescents. Journal of Visual Impairment \& Blindness, 91, 236-244.

Kef, S. (2002). Psychosocial adjustment and meaning of social support for visually impaired adolescents. Journal of Visual Impairment \& Blindness, 20, 22-37.

Kunter, M., Tsai, Y., Klumann, U., Brunner, M., Krauss, S., \& Baumert, J. (2008). Students' and mathematics teachers' perceptions of teacher enthusiasm and instruction. Learning \& Instruction, 18, 468-482.

Lau, S., \& Nie, Y. (2008). Interplay between personal goals and classroom goal structure in predicting student outcomes: A multilevel analysis of person-context interactions. Journal of Educational Psychology, 11, 119-124.

Legault, L., Green-Demer, I., \& Pelletier, L. (2006). Why do high school students lack motivation in the classroom? Toward an understanding of academic motivation and the role of social support. Journal of Educational Psychology, 98(3), 567-582.

McKinney, C. W., Robertson, C. W., Gilmore, A. C., Ford, M. J., \& Larkins, A. G. (1984). Some effects of three levels of teacher enthusiasm on student achievement and evaluation of teacher effectiveness. Journal of Instructional Psychology, 11, 119-124.

Metcalfe, A., \& Game, A. (2006). The reacher's enthusiasm. The Australian Educational Researcher, 33, 91-106.

Nolten, P. W. (1994). Conceptualization and measurement of social support: The development of the Student Social Support Scale Unpublished doctorial dissertation, The University of Wisconsin-Madison. 
Patrick, B. C., Hisley, J., Kempler, T., \& College, G. (2000). "What's everybody so excited about?": The effects of teacher enthusiasm on student intrinsic motivation and vitality. Journal of Experimental Education, 68, 1521-1558.

Rosenfeld, L. B., Richman, J. M., \& Bowen, G. L. (2000). Social support networks and social outcomes: The centrality of teacher. Child and Adolescent Social Work, 17, 205-226.

Ryan, R. M., \& Deci, E. L. (2000). Self-determination theory and the facilitation of intrinsic motivation, social development, and well-being. American Psychologist, 55(1), 68-78.

Schunk, D. H (1989). Self-efficacy and cognitive achievment: Implications for students with learning problems. Journal of Learning Disabilities, 22(1), 14-22.

Shanahan, M. J. (2000). Pathways to adulthood in changing societies: Variability and Mechanisms in life course perspective. Annual Reviews of Sociology, 26, 667-692.

Skinner, E. A., \& Belmont, M. J. (1993). Motivation in the classroom: reciprocal effects of teacher behavior and student engagement across the school year, Journal of Educational Psychology, 85(4), 571-581.

Stipek, D. (1998). Motivation to learn: from theory to practice (전성연· 최병연 공역(1999). 학습동 기. 서울: 학지사).

Thoits, R. A. (1982). Conceptual, methodological and theoretical problems in studying social support as a buffer against life stress. Journal of Health Social Behavior, 23(2), 145-159.

* 논문접수 2013년 11월 4일 / 1차 심사 2013년 12월 3일 / 2차 심사 2014년 2월 17일 / 게재승인 2014년 3월 10일

* 김경희: 전남대학교 교육학과를 졸업하고, 동 대학교에서 교육학석사 및 교육학박사과정을 수료하였다. 현재 동신대학교 원격평생교육원 연구원으로 재직 중이다.

*E-mail: kkhee@dsu.ac.kr

* 라만교: 한양대학교 교육학석사 및 동신대학교 대학원 교육학과에서 교육학박사과정을 수료하였다. 현재 신갈고등학교장으 로 재직 중이다.

*E-mail: mg5373@hanmail.net

* 권재환: 중앙대학교 심리학과를 졸업하고, 연세대학교 교육학석사 및 전남대학교 대학원 교육학과에서 교육학박사학위를 취득하였다. 현재 동신대학교 교육대학원 교수로 재직 중이다.

*E-mail: jhkwon@dsu.ac.kr 


\title{
Verification of a Relational Model among Professor's Support, Learning Motivation, and Academic Adjustment of College Students
}

\author{
Kim, Kyung-hee* \\ $\mathrm{Na}, \mathrm{Man}-\mathrm{gyo}^{\star *}$ \\ Kwon, Jae-hwan ${ }^{* * *}$
}

This study was to verify a related model between among perceived professor's support, learning motivation, and academic adjustment of college students. And to test the mediator effects of learning motivation in the relation between professor's support and academic adjustment. Professor's support was selected as prerequisite variables. And learning motivation was selected as a mediated variable. Which affected college students' academic adjustment. For the purpose the data was gathered through self-reported expression questionnaire responded by the subjects was 240 college students. Correlational analysis and structure equation modeling analysis were conducted to test research questions. The results are summarized as follows. First, professor's support positive impact on learning motivation and academic adjustment, professor's support of sub-factors of emotional support were the most explanatory power. Second, of the models with professor's support as predictor, learning motivation as mediator, and academic adjustment as outcome variable, the partial mediation model fit the data better than the complete mediation model. Third, in the partial mediation model, the path coefficients of (professor's support $\rightarrow$ academic adjustment), (professor's support $\rightarrow$ learning motivation), (learning motivation-academic adjustment) were all significant. Fourth, the mediator effect of learning motivation in the relation between professor's support and academic adjustment was significant. Based on the results of this study, college students how to increase learning motivation and academic adjustment were discussed.

Key words: professor's support, learning motivation, academic adjustment, college student

\footnotetext{
* First author, Researcher, Dongshin University

** Ph.D. Candidate, Dongshin University

*** Corresponding author, Professor, Dongshin University
} 